\title{
Arithmetic Sequence at Gorga
}

\author{
Candra Ditasona ${ }^{1,2}$, Turmudi $^{2}$ and Rizky Rosjanuardi ${ }^{2}$
}

\author{
${ }^{1}$ Mathematics Education Department, Faculty of Teacher Training and Education, Universitas Kristen Indonesia \\ ${ }^{2}$ Mathematics Education Department, Universitas Pendidikan Indonesia, Bandung \\ candraditasona@gmail.com, t_author@xy.mu.edu
}

\begin{abstract}
This research examines the process of making traditional Batak ornaments called gorga. The process will be analyzed mathematical concepts used in making gorga. Based on observations, one of the concepts used in making gorga is arithmetic sequence. This research is aimed at describing the modeling process carried out by engravers using local wisdom (emic) and relating it to academic mathematical modeling (etic). This research involved five gorga carvers in Tobasa and Samosir areas. Data was collected through direct observation, as well as interviews with gorga sculptors. The results showed the existence of arithmetic sequence concepts in the process of making gorga.
\end{abstract}

Keywords: Arithmetic sequences, ethnomathematics, mathematical concept

\section{INTRODUCTION}

Mathematical concept can be found in various daily activities. This can be observed through various activities such as counting, drawing and estimating. Based on the history of mathematics has been used by various groups in different ways (Snipes and Moses, 2001). The study of how mathematical activities are carried out by a group of people we are familiar with the term ethnomathematics.

Ethnomatematics studies the relationship between mathematics and culture (Irfan et al., 2019). Culture means peoples' language, place, traditions, and ways of organizing, interpreting, conceptualizing, and giving meaning to physical and social worlds (Ascher, 1991 p.2). Further, we can define culture as integrated science.

When the International Study Group on Ethnomathematics was established, four general areas of interest were identified: (1) field research, where data about mathematics in culture is collected; (2) mathematical work in cross-cultural situations; (3) classroom applications of ethnomathematics; and (4) theoretical, sociological, and policy studies of ethnomathematics (Rosa et al., 2016).

As a field research, ethnomatemics researchers play a role in providing mathematical interpretations of cultural products and practices so that they can be interpreted mathematically, geometrically, algebraically or with other interpretations in mathematics (Turmudi et al., 2019).

Gorga is a traditional carving of the Batak people that has existed for hundreds of years. As a work of art inherited from generation to generation, gorga has a symbolic and philosophical meaning for the Batak people (Ditasona, 2018). Nowadays gorga can not only be found on the walls of traditional houses, we can also observe gorga on the walls of government offices and public facility buildings in the Tobasa and Samosir areas.

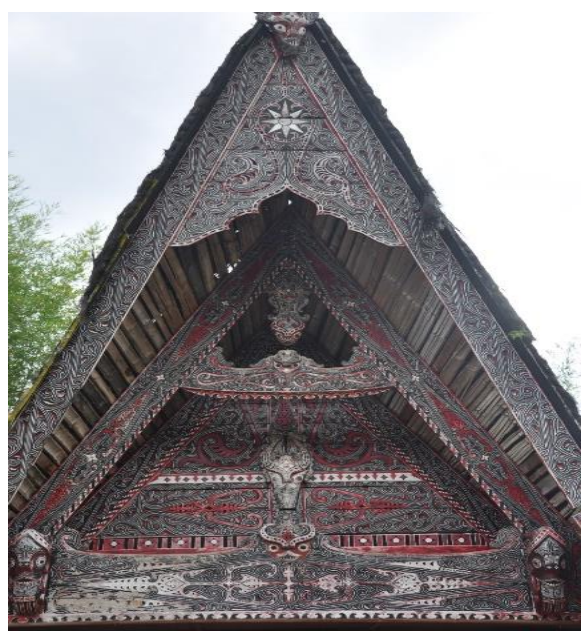

Figure 1: Gorga in the Batak Traditional House 
The shape of the Gorga motif tends to be dense, with a combination of three colours, red, white and black, at a glance the Gorga has a varied and somewhat complicated shape. Then how do the carvers to make Gorga with all its complexity, where did they start the process, are there ideas, mathematical concepts used in the making? In previous studies (Ditasona, 2018) revealed aspects of the geometry transformation found in Gorga. The transformation includes reflection, translation, rotation, and dilation.

Based on the patterns found in the Gorga motifs, it turns out that in some Gorga motifs there is the concept of arithmetic sequences. This study aimed to describe the modelling process carried out by the engraver using local wisdom (emic) and linking it to academic mathematical modelling (etic) (Rosa and Orey, 2010). The focus of this research is to reveal the concept of arithmetic sequences that use local wisdom, which is observed through the activities carried out by carvers to make Gorga. The activity is then associated with the concept of arithmetic sequence that we learn in academic mathematics.

\section{METHOD}

This study involved five Gorga carvers. Two of them were carvers in the area of Tobasa and three others were from Samosir area. Their educational background varies from middle school to high school. They learn the art of carving through the generations of their parents or relatives.

In collecting data the researchers used field notes, photos, videos and direct interviews. Photos are used to collect the types of Gorga carving motifs Photos are used to collect the types of Gorga motifs found on the walls of traditional houses in the Tobasa and Samosir areas. From the motives obtained the use of mathematical ideas will be observed. The video is used to record every stage of the carving process. Interviews were conducted directly at the time of work to find out the mathematical ideas they used and local wisdom to build these ideas.

The form of interview arranged was semi-structured interview. Interviews were conducted to explore information about the mathematical process carried out by the Gorga carvers. Important things to observe in the interview process with sculptors include how they convey their ideas verbally or non-verbally, how these ideas can solve problems, assess each step critically, submit several arguments to confirm.
Mathematical ideas obtained from the engraver group will be analysed and linked to academic mathematical concepts. That will be the findings and discussion in this study.

\section{RESULT AND DISCUSSION}

Although the sculpture of the Gorga looks complicated, it is created using one simple basic pattern. Each Gorga carving has a basic pattern called "mal" (fig.2). Generally, the stages of making gorga are drawing mal, plagiarizing, carving, and painting (fig.3). The first step to making a Gorga is drawing a mal. These basic patterns will be used as a template to draw motifs throughout the board to be carved. In ancient times the mal was painted on bark or leather. Currently, carpenters usually use cardboard to draw mal.

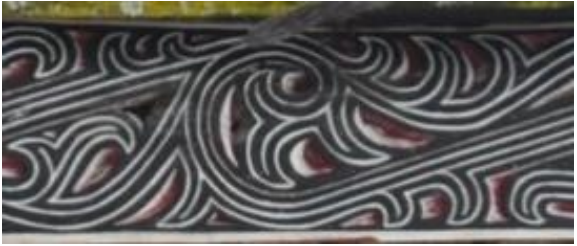

Figure 2: Examples of $\mathrm{mal}$

Then the question arises why you have to make a mal first before drawing a Gorga? Can we draw directly without using the mal? From the results of the carvers' answers it was found that the carvers must use the mal so that the images obtained are more precise in terms of distance, shape and size. The more precision the resulting image, the more beautiful the engraving will be formed. Carvings drawn using the mal will look more beautiful than those without.

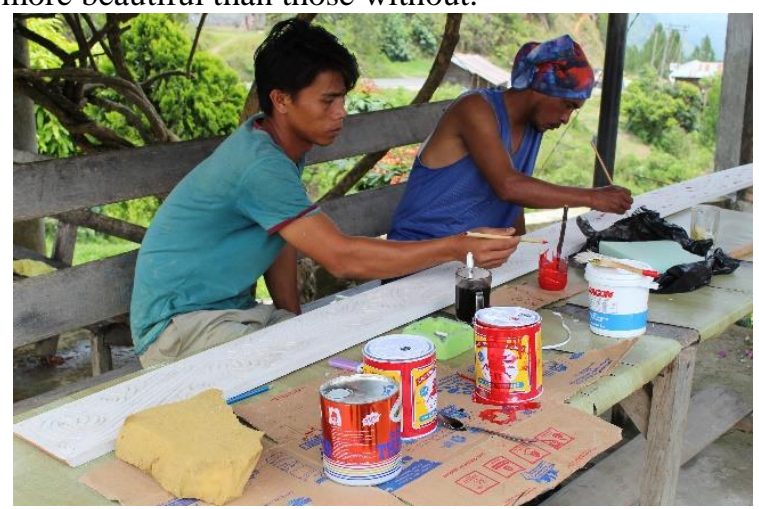

Figure 3: Plank painting process

If you want to draw a mal, the engraver must calculate the dimensions of the board to be carved. To draw a Gorga on the side plank as in Figure 3, the engraver measures the length and width of the board 
and divides the size into several sections so that the size of the mal to be made is obtained. Then the Gorga motif is drawn on the cardboard according to the size of the mal that has been obtained. For example, if you want to draw a board into seven motifs repeatedly, then the length of the board must be divided into seven parts.

How to divide the size of the board also varies between each engraver. Some use the distribution by writing it down on paper, some do the distribution using a calculator on a cellphone, and there is also a simpler way that is using a rope.

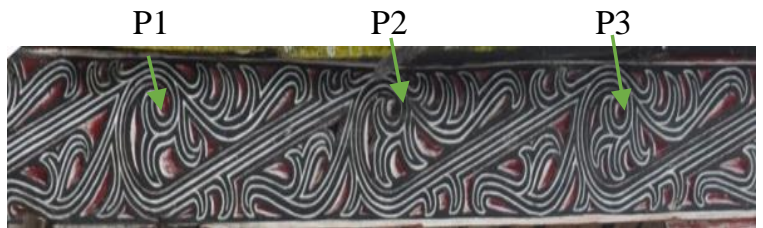

Figure 4: Gorga with translation pattern.

I tried asking the graver who divided using the rope. For those who use rope usually, the motifs to be drawn on the board are always even. The way they do it, first is to fold the rope into two parts, then the folded part is also folded again until a smaller size is obtained. If the size has been obtained then transferred to a cardboard to draw the carving motif.

The next question I ask is what if we just set the size of the mal without having to divide the length of the board. According to them it can be done, but the results of the picture will be less beautiful because there will be motifs that are cut in certain parts of the board. So the process of dividing is done to ensure that the final motif will be right on the drawing at the edge of the board.

As a template mal that have been made are then used to draw side plank. The process is repeated until the entire board is filled with images. In geometry, this process called translation.

Based on the workmanship done by the engraver, the process reflects the concept of the sequence in mathematics. In this case the engraver estimates the arrangement of the motifs on the board with a certain amount. In mathematics we call $n$. In other words, the board will be drawn $U_{1}$ to $U_{n}$, where $n$ is the number of motifs drawn on the board.

If we observe the carving shape in Figure 4, it can be seen that each of the points corresponding to the gorga motif will have the same distance between one motif and another. This distance can be interpreted as the difference. For example $P_{1}$ in figure 4 has a distance $x$ with $P_{2}$, as well $P_{2}$ has a distance $x$ with $P_{3}$. If we plot the picture on Cartesian coordinates $P_{1}(a, b)$ is a translation so the coordinates of:

$$
\begin{gathered}
P_{2}=(a+x, b) \\
P_{3}=(a+x+x, b) \text { or } P_{3}=(a+2 x, b) .
\end{gathered}
$$

So the $n$ point can be written as:

$$
P_{n}=(a+(n-1) x, b)
$$

The shape is a pattern of arithmetic sequence with a difference $x$.

The process of dividing the board to determine mal size mathematically is the process of determining the $n$ term or $U_{n}$. Suppose the engraver divides a piece of board that is 3 meters long and 15 centimeters wide into 10 sections. Then the size of the mal to be made is $30 \mathrm{~cm}$ $\mathrm{x} 15 \mathrm{~cm}$. This means that the 10 th term or 10 th picture will be right at the end of the board. The corresponding points on each image will be $30 \mathrm{~cm}$ apart.

$$
\begin{gathered}
P_{n}=(a+(n-1) x, b) \\
P_{1}=(15,4) \\
P_{10}=(15+(10-1) x, 4) \\
P_{10}=((15+9 x), 4)
\end{gathered}
$$

if $x=30$, then

$$
\begin{gathered}
P_{10}=((15+270), 4) \\
P_{10}=(285,4)
\end{gathered}
$$

Arithmetic sequence patterns on this gorga can usually be found on the decorative motifs of the edge of a traditional house, the geometrical transformation patterns used are usually translation. Translation patterns are not only carried out on a flat plane, the pattern is also found on curved area such as on house poles or barns.

For motifs drawn on curved areas such as the barn pole called "sopo", the method of making is almost the same as on a flat plane. The engraver first measures the circumference of the pole using string or yarn. After the circumference is obtained, the rope is folded into sections so that the size of the mal to be made is obtained. The next stage, the engraver draws the gorga motif according to the size of the mal. The motif is then transferred to the entire surface of the pole by tracing.

Based on observations during the study, it turns out that arithmetic patterns are not only found in translation patterns of gorga motifs. For example in Figure 5 it appears that the transformation pattern of the motif is a 
reflection. From this picture, we also observe the pattern of sequence, that is

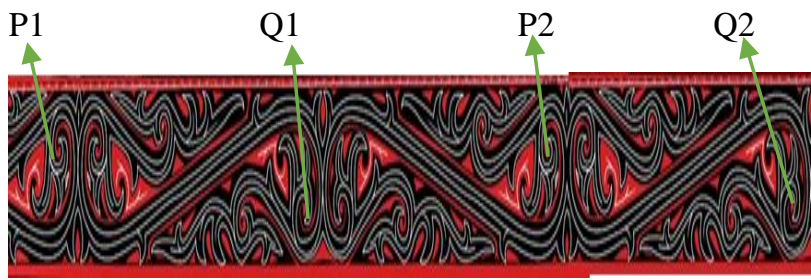

Figure 5: Gorga with reflection pattern

$P_{1}, P_{2}, P_{3}, \ldots, P_{n}$ and $Q_{1}, Q_{2}, Q_{3}, \ldots, Q_{n}$. Suppose $k$ is the distance from $P_{1}, P_{2}$ then the distance $P_{1}, P_{2}$ is equal to the distance $Q_{1}, Q_{2}$ so that $P_{1}, P_{2}, P_{3}, \ldots, P_{n}$ have the same formula as $Q_{1}, Q_{2}, Q_{3}, \ldots, Q_{n}$ in other words:

$$
\begin{aligned}
P_{n} & =(a+(n-1) k, b) \\
Q_{n} & =(a+(n-1) k, b)
\end{aligned}
$$

From the whole process of making gorga, the most determining factor is the process of making mal. The process is at the same time a determinant of the formation of an arithmetic sequence. By drawing using the mal means that each motive will have a fixed distance or in arithmetic sequence we call common difference.

The process of determining the number of motifs to be drawn on the board mathematically is the determination of finite arithmetic sequences. For example, 10 motifs will be drawn on the board, meaning that the arithmetic sequence produced is a finite sequence with the last term being the 10th term. As explained in the previous section, to determine the size of the mal, the engraver must first determine how many motifs will be drawn on the board, after that the mal size is obtained. From this process it can be seen that there are differences in the flow of thought carried out by the group of engravers related to the determination of arithmetic sequences, in the concept of arithmetic sequences it is usually known that it is the first term and the difference, but in the local wisdom practice of the engraver they first determine the last term then the difference is obtained.

Gorga gives an example of another form of arithmetic sequence. If academically we have only known sequence in the form of numbers, the local wisdom of the engravers makes us enjoy arithmetic sequence through Gorga carvings. The pattern of regularity in a sequence when visualized turns out to produce a beautiful carving to be seen.

\section{CONCLUSIONS}

Sequence not only be observed on numbers, but also be engraved like Gorga which has a certain pattern or which has the same distance for each corresponding unit. The process of making $\mathrm{mal}$ in Gorga determines Gorga as arithmetic sequences. Arithmetic sequences are not only found in Gorga motifs that have translation patterns, in motifs formed by the reflection process there are also arithmetic sequences.

In learning of school mathematics, the definition of an arithmetic sequence is focused on numbers, so that students' understanding of arithmetic sequences becomes narrow. As a suggestion, it is necessary to consider integrating local wisdom to enrich students' understanding of arithmetic sequences.

\section{REFERENCES}

[1] Ditasona, C., 2018. Ethnomathematics Exploration of the Toba Community: Elements of Geometry Transformation Contained in Gorga (Ornament on Bataks House). IOP Conf. Ser. Mater. Sci. Eng. 335. 899X/335/1/012042

[2] Irfan, M., Slamet Setiana, D., Fitria Ningsih, E., Kusumaningtyas, W., Adi Widodo, S., 2019. Traditional ceremony ki ageng wonolelo as mathematics learning media. J. Phys. Conf. Ser. 1175.

[3] Katsap, A., Silverman, F.L.R., 2008. A case study of the role of ethnomathematics among teacher education students from highly diverse cultural backgrounds. J. Math. Cult. 3, 66-102.

[4] Rosa, M., D'Ambrosio, U., Orey, D.C., Shirley, L., Alangui, W. V., Palhares, P., Gavarrete, M.E., 2016. Current and Future Perspectives of Ethnomathematics as a Program. Springer. https://doi.org/10.1007/978-3-319-30120-4

[5] Rosa, M., Orey, D.C., 2010. Ethnomodeling: a Pedagogical Action for Uncovering Ethnomathematical Practices. J. Math. Model. Appl. 1, 7011-7020.

[6] Snipes, V., Moses, P., 2001. Linking Mathematics and Culture to Teach Geometry Concepts. LATM J. 1, 1-17.

[7] Turmudi, Juandi, D., Puspita, E., Yuniyawati, 2019. Pendidikan Sains dan Teknologi di Era Revolusi Industri 4.0, in: Hamied, F.A., Komalasari, K. (Eds.), . UPI Press, Bandung. 